\title{
The radiation response of hormone- resistant prostate cancer induced by long-term hormone therapy
}

\author{
Chun-Te Wu ${ }^{1,2}$ Wen-Cheng Chen ${ }^{3}$, Shuen-Kuei Liao', Cheng-Lung Hsu', ${ }^{2,4}$, \\ Kuan-Der Lee ${ }^{2,5}$ and Miao-Fen Chen ${ }^{2,3}$ \\ ${ }^{1}$ Department of Urology, Chang Gung Memorial Hospital, Linko, Taiwan \\ ${ }^{2}$ Graduate Institute of Clinical Medical Sciences, Chang Gung University and Chang Gung Institute of Technology, Taiwan \\ ${ }^{3}$ Department of Radiation Oncology, Chang-Gung Memorial Hospital, Chia-Yi, \#6, Chia-Pu Road, Putz City, Chia-Yi Hsien, Taiwan \\ ${ }^{4}$ Department of Hematology-Oncology, Chang Gung Memorial Hospital, Linko, Taiwan \\ ${ }^{5}$ Department of Medical Oncology, Chang Gung Memorial Hospital, Chiayi, Taiwan \\ (Correspondence should be addresses to M-F Chen; Email: miaofen@adm.cgmh.org.tw)
}

\begin{abstract}
Hormone therapy for prostate cancer eventually fails leading to a stage called hormone-resistant (HR) disease. To investigate the issue about the characteristics and the radiation response in HR prostate cancer, we established HR cell sub-lines, 22RV1-F and 22RV1-DF, from 22RV1 cells with androgen deprivation for 16 weeks, and obtained LNCaP-HR from LNCaP with long-term bicalutamide treatment. We examined their sensitivities to radiation therapy and the underlying mechanisms. In vitro and in vivo faster tumor growth rate was noted in the HR prostate cancer cells when compared with control. Moreover, HR prostate cancer cells had greater capacity to scavenge reactive oxygen species, and suffered less apoptosis and senescence, and subsequently were more likely to survive from irradiation as measured by clonogenic assay in vitroand growth delay in vivo. The decreased p53 and increased mouse double minute 2 oncogene (MDM2) might be the potential underlying mechanisms for the more aggressive growth and more radioresistance in $\mathrm{HR}$ prostate cancer cells. In conclusion, HR prostate cancer cells appeared to be more aggressive in tumor growth and in resistance to radiation treatment. Regulation of the expressions of p53 and MDM2 should be the promising treatment strategies for relative radioresistant prostate cancer.
\end{abstract}

Endocrine-Related Cancer (2007) 14 633-643

\section{Introduction}

Because the initiation and progression of prostate cancer depend on androgen receptors (AR) to mediate the androgen effect in most cases (Chang et al. 1995), standard hormone therapy aims to inactivate AR transcription by androgen deprivation (through surgical or medical castration). However, the essential most of prostate cancers that show initial favorable regression after androgen deprivation eventually become a hormone-resistant (HR) phenotype (Tilley et al. 1996, Craft et al. 1999). There is increasing evidence that several mechanisms contribute to the androgen-independent progression of HR prostate cancer cells, including AR mutation, AR overexpression, and p53 status (Tepper et al. 2002, Hara et al. 2003, Chen et al. 2004). P53 could regulate AR-mediated signaling in prostate cancer cell lines (Sengupta \& Wasylyk 2001,
Shenk et al. 2001, Cronauer et al. 2004), and reduction of p53 function by antisense p53 contributes to the phenotype of HR prostate cancer cells (Agus et al. 1999, Burchardt et al. 2001). Moreover, p53 plays a central role in detecting DNA damage and is crucial for the responses to treatment of various cancers (Polyak et al. 1997, Sablina et al. 2005, Chen et al. 2006a). Therefore, we proposed that HR prostate cancer might appear to be different in treatment responses in addition to tumor characteristics when compared with androgensensitive cells.

Radiation therapy (RT) is an important treatment modality for localized prostate cancers. Clinical trials have shown that a combination of hormone treatment (neoadjuvant and adjuvant) and curative radiation treatment leads to better local control and diseasefree survival of prostate cancer patients than radiation 
treatment alone, especially for high-risk patients (Roach 1999, Lee 2006). However, to our knowledge, there are few studies to demonstrate the difference of the radiation response between androgen-sensitive and HR prostate cancer cells. Furthermore, the patients with history of long-term hormone treatment seemed to have higher biochemical failure rates after RT, according to the preliminary clinical observation in our department. It triggers an unsolved issue in clinical; if the prognosis and the response to standard curative treatment might be different between patients with HR prostate cancer induced by too long-term hormone treatment and those with androgen-sensitive prostate cancer.

Therefore, we investigated the tumor growth, sensitivity to irradiation, and the cellular mechanisms that may facilitate resistance to irradiation, in human HR prostate cancer cells by the experiments in vitro and in vivo.

\section{Materials and methods}

\section{Cell cultures}

Human prostate cancer cells, LNCaP, 22RV1, and PC-3, were obtained from the American Type Culture Collection, and maintained in RPMI 1640 medium (Gibco, Carlsbad, CA, USA) with 10\% FBS. LNCaP and 22RV1 are androgen-responsive prostate cancer cell lines. However, in contrast to androgen-dependent growth of LNCaP, 22RV1 can grow in androgendeprived medium, with slower proliferation rate. To establish the HR cells from 22RV1, we cultured 22RV1 cells in RPMI with $10 \mathrm{nM}$ flutamide (antiandrogen; Sigma Chemical Co.), and with $10 \%$ fetal bovine serum (FBS) or 10\% dextran-coated charcoaltreated fetal bovine serum (DCC-FBS). The culture conditions were intended to mimic the clinical situation in which the prostate cancer patients receive hormone therapy. After 16 weeks of culture, these cells grew significantly faster than 22RV1 in $10 \%$ FBS without flutamide (22RV1-C) and those were designated as 22RV1-HR (22RV1-F and 22RV1-DF). $22 \mathrm{RV} 1-\mathrm{F}$ was generated in androgen-containing medium with anti-androgen treatment, and 22RV1$\mathrm{DF}$ in androgen-depleted medium with anti-androgen treatment. LNCaP-HR cells were obtained form LNCaP after long-term (more than 16 weeks) culture in RPMI with $10 \%$ FBS and $2 \mu \mathrm{M}$ bicalutamide (obtained from Zeneca). In addition, PC-3 is an androgen-independent prostate cancer cell line that expresses neither AR nor p53.

\section{Cell growth and clonogenic assay}

For time-course studies, cells were seeded in six-well plates $\left(1 \times 10^{5}\right.$ cells/well $)$ and counted with a particle counter over 8 days. To determine the intrinsic cellular radiosensitivity, we used a clonogenic assay. Exponentially growing cells were irradiated with single doses of $0,3,6$ or 9 Gy using a $6 \mathrm{MeV}$ electron beam, and then immediately counted, diluted, and plated on $60 \mathrm{~mm}$ culture dishes. After incubation at $37{ }^{\circ} \mathrm{C}$ for 14 days, the plates were stained with crystal violet (Sigma) for colony counting. Colonies containing more than 50 cells were scored, and plating efficiency and surviving fractions were determined for each cell line. To determine the effects of concurrent flutamide treatment on radiation-induced cell death, cells were pretreated with $10 \mathrm{nM}$ flutamide for 3 days before irradiation. After irradiation, flutamide was retained in the cell culture for a further $24 \mathrm{~h}$ and then the media were replaced. To examine the sensitization to radiation by genistein ( $\mathrm{Li}$ et al. 2005), cells were pretreated with $60 \mu \mathrm{M}$ genistein (Sigma Chemical Co.) for $24 \mathrm{~h}$ before irradiation. After irradiation, genistein was retained in the cell culture for a further $24 \mathrm{~h}$.

\section{Immunoblot analysis}

The cells were disrupted in lysis buffer: $50 \mathrm{mM}$ Tris ( $\mathrm{pH}$ 8.0), $120 \mathrm{mM} \mathrm{NaCl}, 0.5 \% \mathrm{NP} 40,10 \mu \mathrm{g} / \mathrm{ml}$ phenylmethylsulfonylfluoride, and $1 \times$ protease inhibitor cocktail (Calbiochem, La Jolla, CA, USA). Protein concentrations were determined by a Coomassie Blue assay (Bio-Rad). Equal amounts of protein were loaded on SDS-PAGE gels. After electrophoresis, the proteins were transferred to nitrocellulose membrane. The blot was probed with anti-p53, anti-MDM2, and anti-AR antibodies (Santa Cruz Biotechnology, Santa Cruz, CA, USA) and then the membrane was incubated with horseradish peroxidase-conjugated second antibody and detected by enhanced chemiluminescence (ECL). The membrane was re-probed with 1:1000 diluted mouse anti- $\beta$-actin or anti-r-tubulin antibodies to normalize the protein loading. To directly determine the effect of p53 on AR expression in vitro, 22RV1 was transfected with wild-type p53 expression plasmid $\left(\mathrm{V}_{\mathrm{p} 53}\right.$; Chen et al. $2006 a$ ). The protein was extracted $36 \mathrm{~h}$ after transfection.

\section{Intracellular free radical generation}

$2^{\prime} 7^{\prime}$-dichlorofluorescein diacetate (DCFH-DA) is an indicator of intracellular $\mathrm{H}_{2} \mathrm{O}_{2}$ and free radicals (Shenk et al. 2001). Briefly, cells were washed with PBS and incubated in phenol red-free and serum-free medium containing $20 \mu \mathrm{M}$ DCFH-DA for $15 \mathrm{~min}$, then 
treated with $6 \mathrm{~Gy}$ irradiation for $1 \mathrm{~h}$; controls were untreated. $\mathrm{H}_{2} \mathrm{O}_{2}$ oxidizes DCFH to DCF; DCF fluorescence was detected by a flow cytometer equipped with a $488 \mathrm{~nm}$ argon laser.

\section{Senescence-associated- $\beta$-galactosidase (SA- $\beta$-Gal) activity}

SA- $\beta$-Gal is a biomarker for senescent cells. We determined SA- $\beta$-Gal activity using a senescence detection kit from BioVision (Mountain View, CA, USA) according to the manufacturer's instructions. One week after 3 Gy irradiation, cells were treated with fixative solution in 12-well cultures and then incubated with the SA- $\beta$-Gal staining solution at $37{ }^{\circ} \mathrm{C}$ overnight. Senescent cells were identified by blue staining under standard light microscopy. A total of 1000 cells were counted in five random fields to determine the percentage of SA- $\beta$-Gal-positive cells.

\section{Flow cytometric analysis for apoptosis}

Cells were irradiated (6 Gy in a single fraction) with a $6 \mathrm{MeV}$ electron beam generated by a linear accelerator at a dose rate of $300 \mathrm{cGy} / \mathrm{min}$. Apoptosis was determined by the percentage of cells staining positively for Annexin V and PI $12 \mathrm{~h}$ after irradiation (Pharmingen, San Diego, CA, USA). To directly determine the effects of p53 and MDM2 on the death of 22RV1-C and 22RV1-DF cells respectively, we detected apoptosis in 22RV1-C $24 \mathrm{~h}$ after transfection with p53 siRNA, and in 22RV1-DF $24 \mathrm{~h}$ after $60 \mu \mathrm{M}$ genistein treatment (Li et al. 2005).

\section{Immunoprecipitation}

Immunoprecipitation was performed as described previously (Chen et al. 2006b). MDM2 was immunoprecipitated from prostate cancer cells by anti-MDM2AC (Santa Cruz). The immunoprecipitates were collected by centrifugation at $10600 \mathrm{~g}$ for $5 \mathrm{~min}$ in a microfuge, resuspended in $10 \mu \mathrm{l}$ of denaturing solution (10\% SDS, $4.5 \%$ B-mercaptoethanol) and subjected to western blotting with anti-AR.

\section{Tumor xenografts}

Cells $\left(1 \times 10^{6}\right.$ cells per animal and five animals per group) were subcutaneously implanted on the right dorsal gluteal region of 5-week-old male Balb/c nude mice with castration or control condition. The tumor size was measured every 3 days after each tumor cell type was seeded into the animals (day 0 ). The tumor volume was calculated assuming an ellipsoid shape. To determine the effect of androgen on tumor growth, the growth curves of the tumors in castrated nude mice were determined by the relative volumes, normalized to the volume in control male mice at day 21 around $1 \mathrm{~cm}^{3}$ for each cell type respectively. Furthermore, we determine the radiation sensitivity for each cell type in vivo, irradiation with 20 Gy was performed at day 21 in male nude mice and the tumor size was measured every 3 days subsequently. The radiosensitivities of different xenografts were indicated by growth delay, i.e., the time required after irradiation for the tumor to recover its previous volume.

\section{Results}

\section{Cell growth in vitro}

The effects of long-term hormone treatment on human prostate cancer cells were determined by growth curves, first. We counted the number of cells from day 0 to day 8 , when cells were treated with different durations of androgen deprivation. After 2 weeks of culture, 22RV1 cells in RPMI with $10 \mathrm{nM}$ flutamide and either $10 \%$ FBS or $10 \%$ DCC-FBS grew more slowly than 22RV1-C; but 22RV1 cells in RPMI with $10 \mathrm{nM}$ flutamide and $10 \%$ FBS started to grow faster than 22RV1-C after 4 weeks (Fig. 1A). 22RV1 cells with $10 \%$ DCC-FBS appeared to grow more rapidly than 22RV1-C up to 8 weeks of androgen deprivation (Fig. 1B). After 16 weeks of anti-androgen treatment, Fig. 1C shows that 22RV1-HR (22RV1-F and 22RV1DF) grew significantly faster than $22 \mathrm{RV} 1-\mathrm{C}$ and were at a similar rate to PC-3 cells. In addition, we found that LNCaP-HR also appeared to have significantly rapid growth than control cells (Fig. 1D).

\section{Tumor growth in vitro}

For in vivo measurements, five xenograft tumors from each cell type were checked by pathologists after $\mathrm{H} \& \mathrm{E}$ staining (Fig. 2A). Figure 2B shows that 22RV1-C was androgen-sensitive prostate cancer cells with significantly slower tumor growth in castrated mice when compared with those in control mice. As shown in Fig. $2 \mathrm{C}$ and $\mathrm{D}$, androgen deprivation had no inhibitory effect in 22RV1-DF xenografts, while partially inhibiting the growth of 22RV1-F xenografts.

\section{Response to radiation treatment}

The effects of androgen deprivation on radiation sensitivity were determined by clonogenic assay and tumor growth delay. Androgen-sensitive and HR Cells were exposed to single radiation doses of $0,3,6$, or $9 \mathrm{~Gy}$, and their survival curves were determined by 
colony-forming assays. Figure $3 \mathrm{~A}$ shows that concurrent androgen deprivation failed to radiosensitize 22RV1 cells. In contrast, HR cells induced by longterm androgen deprivation had significantly greater
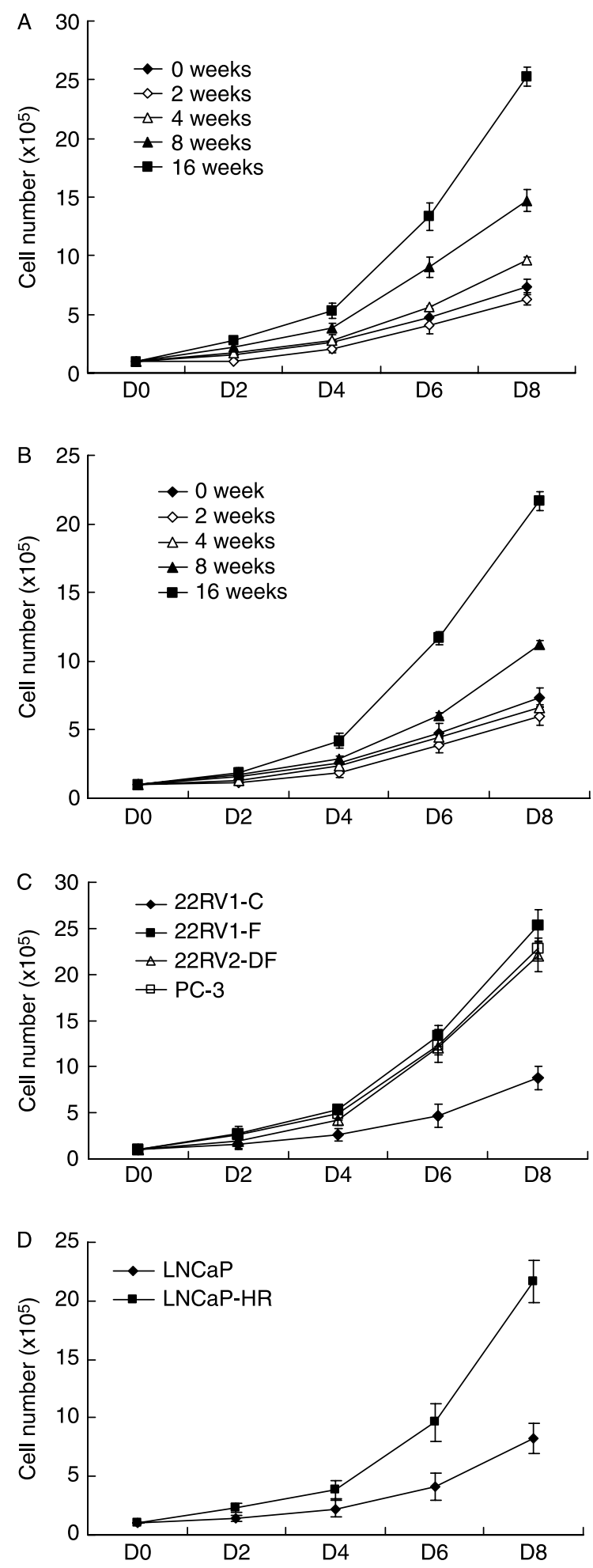

radioresistance when compared with control cells, which was noted in both 22RV1 and LNCaP (Fig. 3B and $\mathrm{C})$. To determine the radiation sensitivity in vivo, irradiation was performed when tumors grew into around $1 \mathrm{~cm}^{3}$ in nude mice. The tumors were exposed to a single radiation dose of $20 \mathrm{~Gy}$ and the growth delay was determined by measuring tumor size every 3 days after irradiation. The growth delays for 22RV1C, 22RV1-F, and 22RV1-DF were 18, 12, and 9 days respectively. The results showed that 22RV1-DF xenografts appeared more radioresistant (Fig. 3D).

\section{Increase of ROS, apoptosis, and senescence after irradiation}

ROS are thought to be important mediators of radiation damage. We measured intracellular ROS in 22RV1-C and 22RV1-HR cells $1 \mathrm{~h}$ after $6 \mathrm{~Gy}$ irradiation. Intracellular ROS levels were lower in 22RV1-HR than in 22RV1-C with and without irradiation (Fig. 4A). The similar presentation was noted in LNCaP-HR and LNCaP cells (Fig. 4B). The apoptosis rate $12 \mathrm{~h}$ after 6 Gy irradiation treatment was increased from $13.1 \pm 3.1$ to $27.9 \pm 2.5 \%$ in $22 \mathrm{RV} 1$, from $7.5 \pm$ 2.3 to $13.3 \pm 2.4 \%$ in $22 \mathrm{RV} 1-\mathrm{F}$, and from $6.7 \pm 2.1$ to $12.6 \pm 1.8 \%$ in $22 \mathrm{RV} 1-\mathrm{DF}$ as revealed by Annexin V and PI staining (Fig. 4C). In addition, we demonstrated by SA- $\beta$-Gal staining that 6 Gy irradiation increased cellular senescence in 22RV1 significantly more than in 22RV1-F and 22RV1-DF, 1 week after irradiation $(40 \pm 5.7,23 \pm 3.5$, and $21 \pm 2.9 \%$ respectively; Fig. 4D).

\section{p53 and MDM2 expression}

We examined p53 expression by western blotting, in irradiated and non-irradiated cells, to determine whether 553 plays a role in the more rapid proliferation

Figure 1 Growth curves of prostate cancer cells after different regimens and durations of hormone treatment in vitro. (A) The $22 \mathrm{RV} 1$ cells $\left(1 \times 10^{5}\right.$ cells/well) were plated in six-well plates after $0,2,4,8$, and 16 weeks of culture in RPMI with $10 \mathrm{nM}$ flutamide and $10 \%$ FBS. The growth curves were obtained by plotting the number of viable cells for 8 days, as a function of time in culture. (B) The 22RV1 cells $\left(1 \times 10^{5}\right.$ cells/well) were plated in six-well plates after $0,2,4,8$, and 16 weeks of culture in RPMI with $10 \mathrm{nM}$ flutamide and 10\% DCC-FBS. The growth curves were obtained by plotting the number of viable cells for 8 days, as a function of time in culture. (C) The cells (22RV1-C, 22RV1-F, 22RV1-DF, and PC-3) were seeded in culture dishes and grown for 8 days. The growth curves were obtained by plotting the number of viable cells as a function of time in culture. (D) LNCaP and LNCaP-HR cells were seeded in culture medium without or with bicalutamide and grown for 8 days respectively. The growth curves were obtained by plotting the number of viable cells as a function of time in culture. 

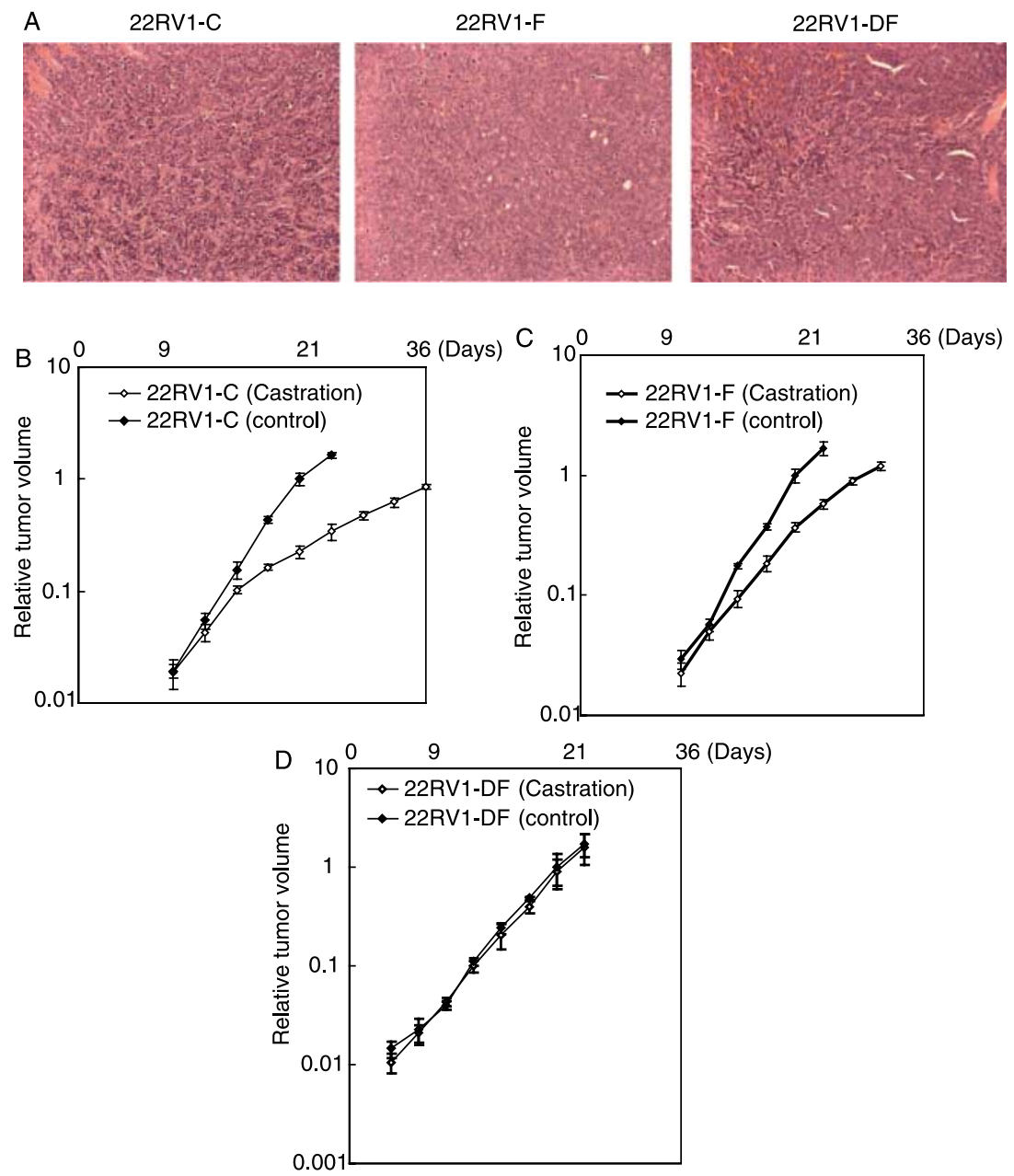

Figure 2 Tumor growth of prostate cancer cell xenografts. (A) Five xenograft tumors from each cell type were checked, representative slides were H\&E staining (magnification $\times 200$ ). (B) Tumor growth curves of $22 \mathrm{RV} 1$ xenografts; $1 \times 10^{6}$ cells were injected into the s.c. space of nude mice. The tumor growth curves in nude mice were determined by the relative tumor volumes. The relative tumor volumes were normalized to the volume in control male mice at day 21 around $1 \mathrm{~cm}^{3}$. Androgen deprivation significantly inhibited the 22RV1 xenograft growth. (C) Tumor growth curves of $22 \mathrm{RV} 1-\mathrm{F}$ xenografts; $1 \times 10^{6}$ cells were injected into the s.c. space of nude mice. The tumor growth curves in nude mice were determined by the relative tumor volumes, normalized to the volume in control male mice at day 21 . The 22RV1-F xenograft growth appeared partly androgen responsive. (D) Tumor growth curves of 22RV1-DF xenografts; $1 \times 10^{6}$ cells were injected into the s.c. space of nude mice. The tumor growth curves in nude mice were determined by the relative tumor volumes, normalized to the volume in control male mice at day 21 . The 22RV1-DF xenograft growth appeared androgen unresponsive.

and less radiosensitivity of HR cells. As shown in Fig. 5A, HR cells expressed less p53 than control in 22RV1 and LNCaP. We further measured the apoptosis rate in 22RV1 after transfection with p53 siRNA. Figure 5B reveals that inhibition of p53 decreased the apoptosis rate in 22RV1-C with or without irradiation. Moreover, the increased MDM2 expression was also noted in HR cells (Fig. 5C). To further demonstrate the role of MDM2 in the radiosensitivity, we regulated the MDM2 expression by genistein. We performed western blot analysis and clonogenic assays on these cell lines after genistein treatment. As shown in Fig. 5D, MDM2 was inhibited by $60 \mu \mathrm{M}$ genistein in irradiated 22RV1-HR, and the decrease of MDM2 was associated with increased p53. Moreover, clonogenic assays showed that downregulated MDM2 by genistein increased the radiosensitivity of 22RV1-HR in addition to causing cytotoxicity (Fig. 5E).

\section{AR expression}

AR expression, which is regulated by p53, is reportedly altered in AI prostate cancer cells. Moreover, AR is 
ubiquitinated by an E3 ligase, MDM2. To investigate further the relationship between AR expression and the status of $\mathrm{p} 53$ and MDM2, we measured AR expression and the interaction between AR and MDM2 in control and HR cells. In vitro, AR expression was greater in HR than in control cells (Fig. 6A). In addition,
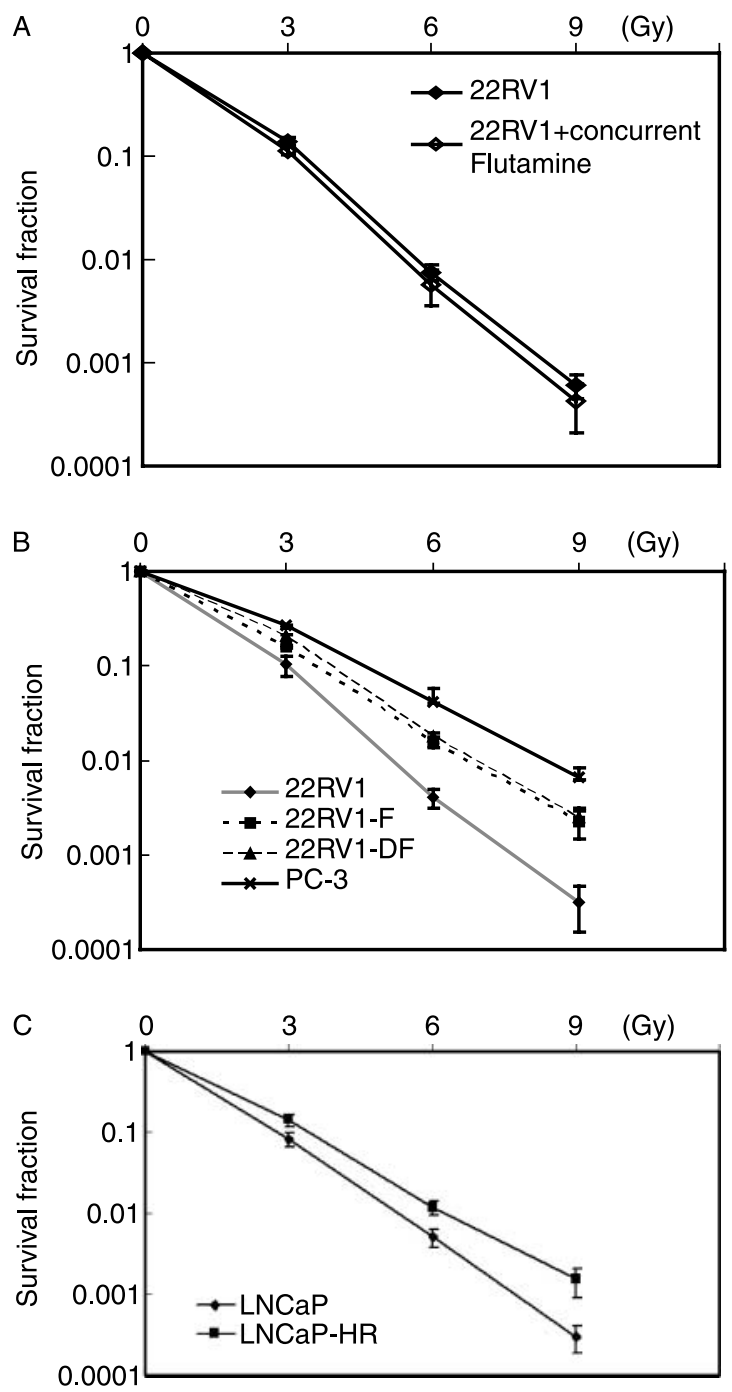

D

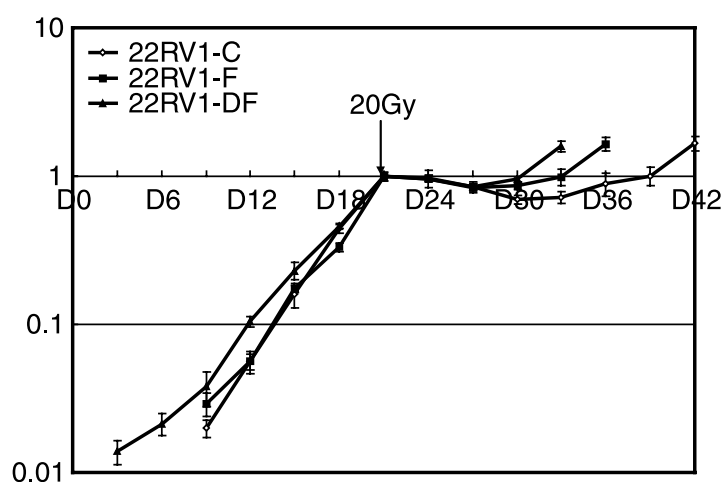

22RV1-HR xenograft tumors also appeared to have higher AR expression in vivo (Fig. 6B). After up-regulation of $\mathrm{p} 53$ by transfection with $\mathrm{V}_{\mathrm{p} 53}$ in 22RV1-C, AR expression was decreased (Fig. 6C). However, we did not find the decreased AR expression in 22RV1-F and 22RV1-DF from immunoprecipitation experiments using antibody against MDM2 (Fig. 6D).

\section{Discussion}

Before the initiation of high dose rate (HDR) prostate brachytherapy in our hospital, some patients with localized prostate cancer refused to receive definite external radiotherapy or surgery and were treated with long-term hormone therapy alone. Because of rising prostate specific antigen (PSA), 12 patients came to receive re-staging and HDR brachytherapy in the first year. According to our clinical observation, the abovementioned 12 patients had significantly lower 5-year biochemical failure-free rates when compared with the other 39 patients with similar stage distributions but without long-term hormone therapy (50 vs $84 \%$, $P=0.0069$ ). Although the number of patients is limited, we hypothesize that the response of HR prostate cancer is different from that of androgensensitive prostate cancer. To test the hypothesis and investigate the underlying mechanisms further, we examined the tumor characteristics of HR prostate cancer cells in vitro and in vivo. It was noted that both 22RV1-F and 22RV1-DF proliferated more aggressively than 22RV1-C in vitro. However, in vivo, the 22RV1-F experienced partial androgen dependence with less rapid tumor growth in castrated mice than that in control mice. The discrepancy in tumor growth of 22RV1-F in vitro and in vivo might be possible due to flutamide withdrawal syndrome (Veldscholte et al. 1992, Schellhammer et al. 1997). The 22RV1-DF xenografts, which, induced by the condition mimic the clinical total androgen block situation, demonstrated

Figure 3 Radiation sensitivity of prostate cancer cells after hormone therapy. (A) Clonogenic assay was performed with 22RV1 cells grown in RPMI with or without $10 \mathrm{nM}$ flutamide for 3 days before irradiation. The survival curve was determined by colony counting and plating efficiency. Each point is an average of three experiments. (B) The cells (22RV1-C, 22RV1-F, 22RV1-DF, and PC-3) were irradiated with $0,3,6$, or 9 Gy, and the survival curves were determined by the colony-forming assay. Each point is an average of three experiments. (C) The cells (LNCaP and LNCaP-HR) were irradiated with 0,3 , 6 , or $9 \mathrm{~Gy}$, and the survival curves were determined by the colonyforming assay. Each point is an average of three experiments. (D) Tumor growth delay of irradiated xenografts. The radiosensitivity of different xenografts is shown as growth delay after irradiation. 22RV1-DF appeared more radioresistant as shown by the decreased growth delay. 
A

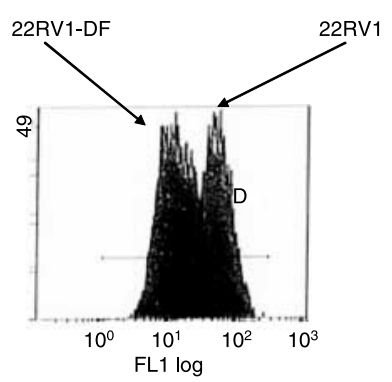

Control

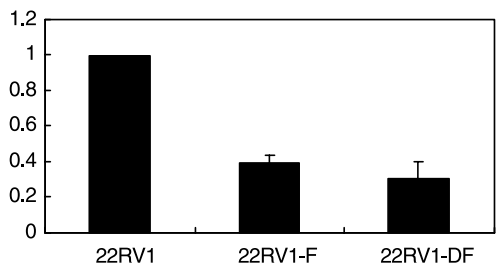

1h after 6Gy
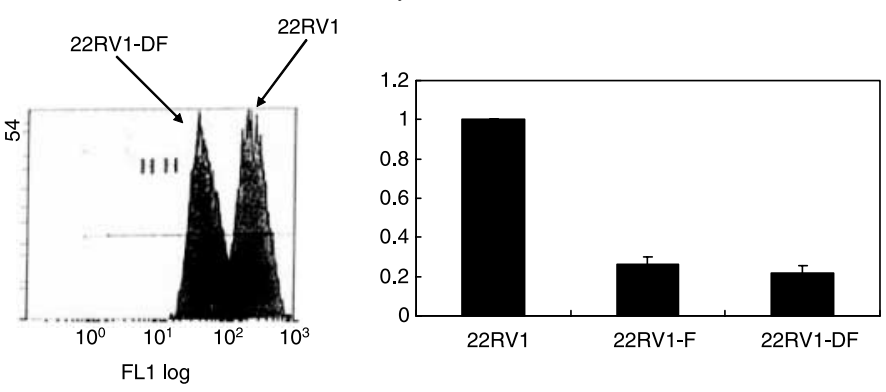

C
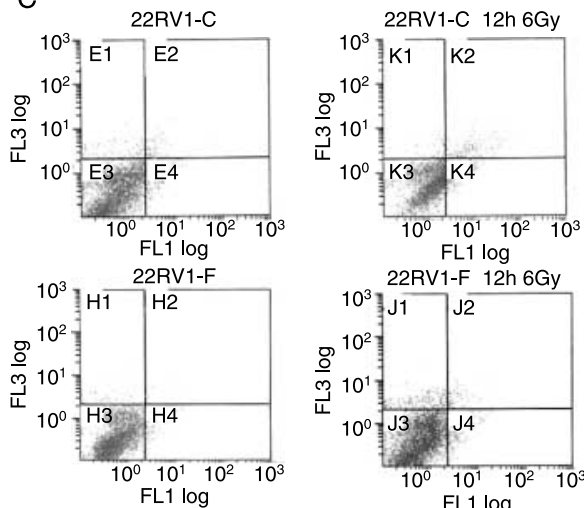

FL1 log

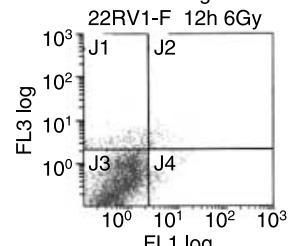

22RV1-DF

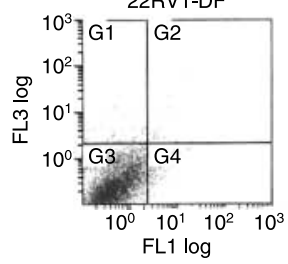

B

Control
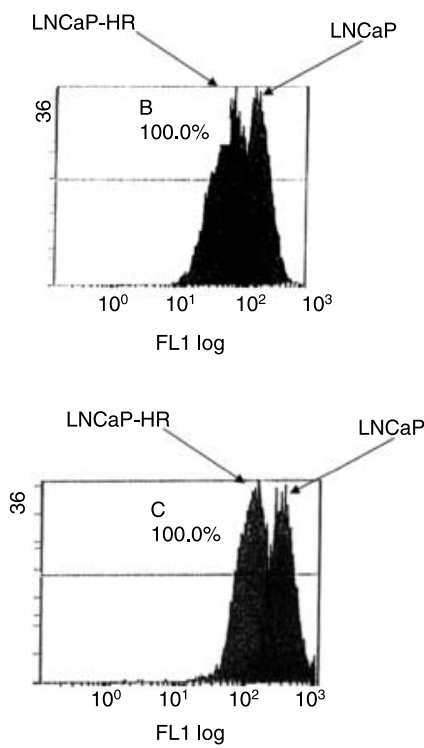

D

Control 22RV1-C 22RV1-F
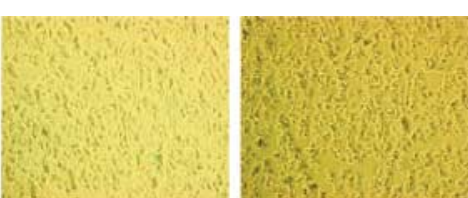

1 wk after 3Gy
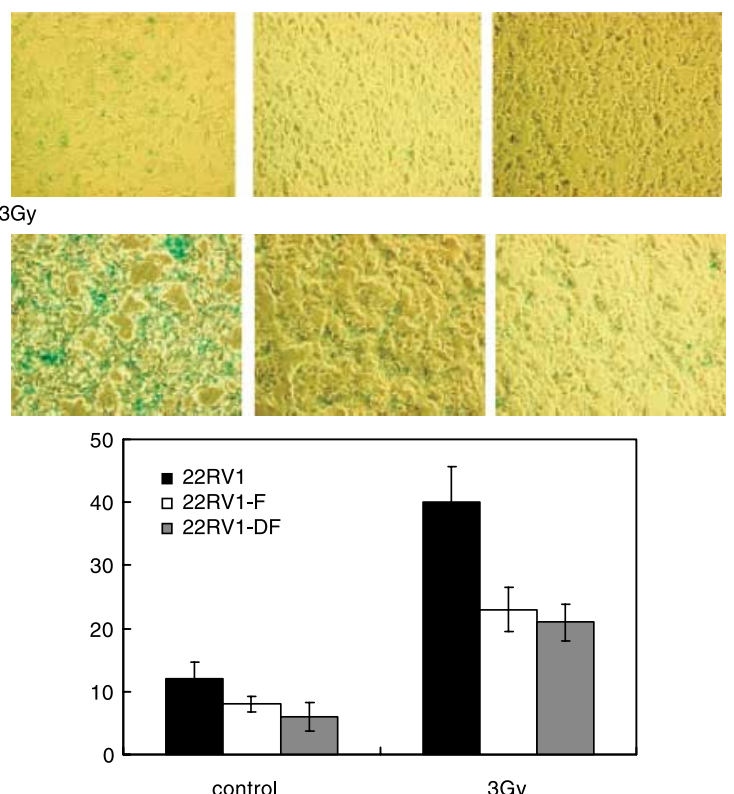

Figure 4 Flow cytometric analysis of ROS and apoptosis in irradiated prostate cancer cells. (A) The intracellular level of ROS was measured by the fluorescent dye DCFH-DA in 22RV1 cells, either control or $1 \mathrm{~h}$ after 6 Gy irradiation. The data are presented as means \pm S.E.M. of three independent experiments ( $y$-axis represents the relative level, normalized by the level of ROS in 22RV1-C). (B) The intracellular level of ROS was measured by the fluorescent dye DCFH-DA in LNCaP cells, either control or $1 \mathrm{~h}$ after 6 Gy irradiation. (C) Flow cytometric analysis using Annexin V staining for apoptosis in 22RV1 cells, either without irradiation or $12 \mathrm{~h}$ after 6 Gy irradiation. (D) The percentage of SA- $\beta$-Gal-positive MSCs in control and irradiated groups was determined by counting 1000 cells. Data are represented as mean \pm S.E.M. 


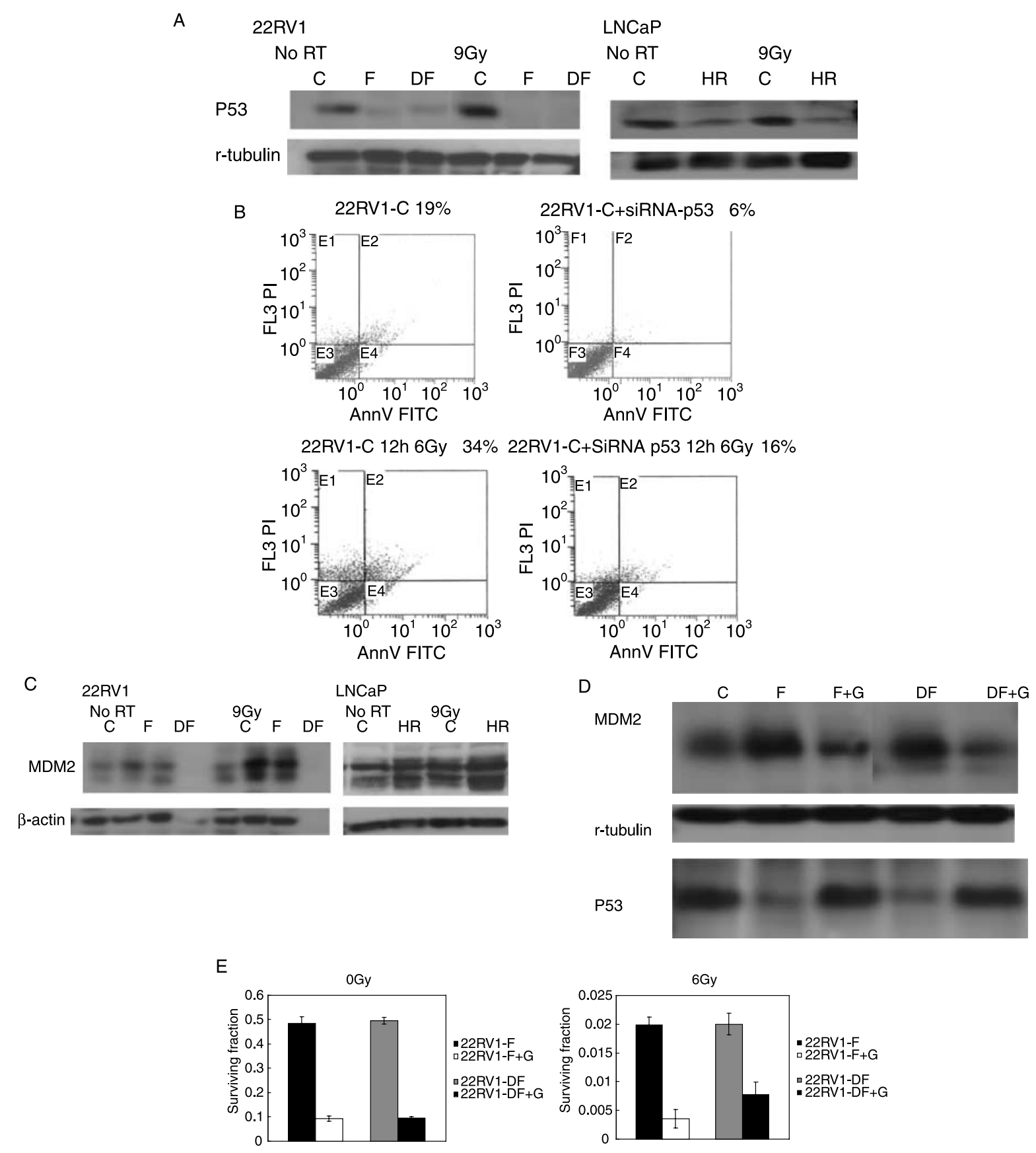

Figure 5 Expression of p53 and MDM2 in prostate cancer cells. (A) Decreased p53 expression was noted in HR cells with or without irradiation as measured by western blot analysis. (22RV1: C, 22RV1-C; F, 22RV1-F; DF, 22RV1-DF. LNCaP: C, LNCaP; HR, LNCaP-HR.) Equal amounts of protein $(50 \mu \mathrm{g})$ were loaded on each lane and the electropherograms were probed by immunoblotting for p53. (B) Flow cytometric analysis using Annexin V staining for apoptosis in 22RV1-C cells $24 \mathrm{~h}$ after transfection with p53 siRNA with or without irradiation. (C) Increased MDM2 expression was noted in HR cells with or without irradiation as measured by western blot analysis. (22RV1: C, 22RV1-C; F, 22RV1-F; DF, 22RV1-DF. LNCaP: C, LNCaP; HR, LNCaP-HR.) Equal amounts of protein $(50 \mu \mathrm{g})$ were loaded on each lane and the electropherograms were probed by immunoblotting for MDM2. (D) Decreased MDM2 and increased $\mathrm{p} 53$ were noted in 22RV1-F and 22RV1-DF $24 \mathrm{~h}$ after treatment with $60 \mu \mathrm{M}$ genistein, as measured by western blotting (C, 22RV1-C; F, 22RV1-F; DF, 22RV1-DF; F \pm G, 22RV1-F after treatment with $60 \mu \mathrm{M}$ genistein; DF $\pm \mathrm{G}, 22 \mathrm{RV} 1-\mathrm{DF}$ after treatment with $60 \mu \mathrm{M}$ genistein). (E) Cells (22RV1-F and 22RV1-DF) were treated with genistein and irradiation. The surviving fractions were determined by the colony-forming assay, the ratio of colonies produced to cells plated. Each point is an average of three experiments. Cells were radiosensitized by pretreatment with $60 \mu \mathrm{M}$ genistein for $24 \mathrm{~h}$ before irradiation. Following irradiation, genistein was retained in the cell culture for a further $24 \mathrm{~h}$. 
A

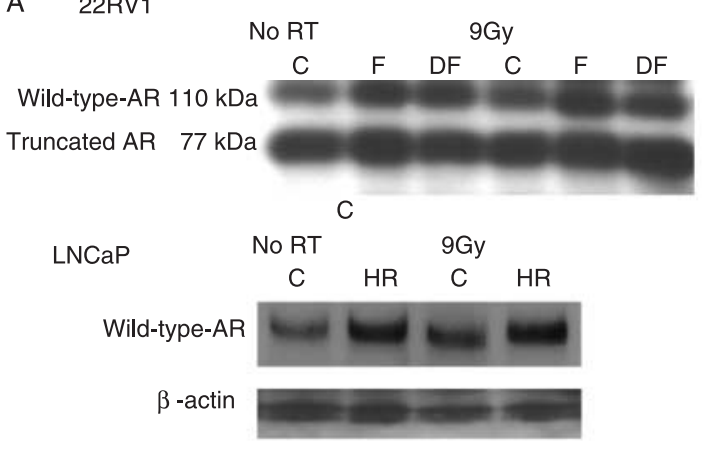

B

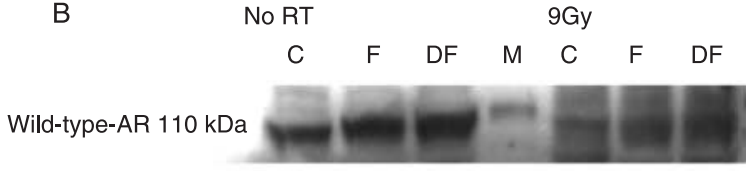

C

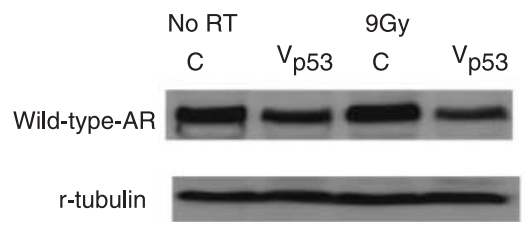

D

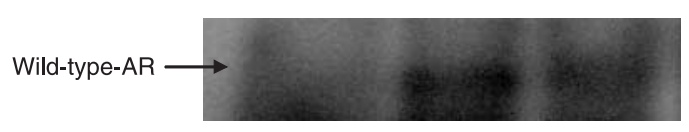

r-tubulin

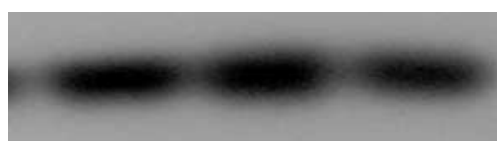

Figure 6 Expression of $A R$ in prostate cancer cells. (A) In vitro increased expression of AR was noted in HR cells with or without irradiation as measured by western blot analysis. (22RV1: C, 22RV1-C; F, 22RV1-F; DF, 22RV1-DF. LNCaP: C, LNCaP; HR, LNCaP-HR.) Equal amounts of protein $(80 \mu \mathrm{g})$ were loaded on each lane and the electropherograms were probed by immunoblotting for AR. (B) In vivo increased expression of AR was noted in 22RV1-F and 22RV1-DF with or without irradiation as measured by western blot analysis. (22RV1: C, 22RV1-C; F, 22RV1-F; DF, 22RV1-DF.) The proteins were extracted from xenograft tumors for $12 \mathrm{~h}$ with or without 20 Gy irradiation. (C) Decreased expression of AR was noted in 22RV1-C cells after transfection with $\mathrm{V}_{\mathrm{p} 53}$ with or without irradiation as measured by western blot analysis. (D) The levels of AR and MDM2 complex were quantified by co-immunoprecipitation. Protein extracts from 22RV1-C, 22RV1-F, and 22RV1-DF cells were precipitated with MDM2-AC antibodies.

rapid tumor growth independantly of androgen treatment. We further examined the effects of antiandrogen treatment on radiation response of prostate cancer cells. Similar to other study, concurrent antiandrogen treatment had no radiosensitization effect
(Pollack et al. 2001). However, the HR cells induced by long-term anti-androgen treatment appeared more radioresistant than the androgen-sensitive 22RV1 cells. Although 22RV1 cells, like the LNCaP, have androgen-responsive $\mathrm{AR}$ and $\mathrm{p} 53$ expression (Tepper et al. 2002, van Bokhoven et al. 2003, Cronauer et al. 2004), they expressed a truncated AR and exhibited a partial androgen-insensitive type (Tepper et al. 2002). Therefore, we further examined the cellular growth and radiosensitivity in LNCaP-HR. Similar to the presentation of $22 \mathrm{RV} 1$, the more rapid growth and radioresistance were noted in LNCaP-HR when compared with $\mathrm{LNCaP}$ cells.

Ionizing radiation can induce many different cell death processes, including apoptosis, necrosis, mitotic catastrophe, and senescence, and the biological effects of RT are largely mediated by reactive oxygen intermediates (Hall 2000, Tulard et al. 2003, Brown \& Attardi 2005). In this study, more RT-induced apoptosis, cellular senescence, and a greater increase of ROS were noted in control cells when compared with HR cells. P53 plays an important role in the ability of scavenging ROS and DNA repair, and potentially contributes to the increased cell death and radiosensitivity (Achanta \& Huang 2004, Sablina et al. 2005, Chen et al. 2006a). Moreover, several studies revealed that the reduced p53 could induce prostate cancer cells to become androgen unresponsive and decrease the apoptosis induced by androgen deprivation (Colombel et al. 1995, Burchardt et al. 2001). Therefore, we further examined the status of p53 in HR. A significant decrease of p53 expression was noted in HR cells with or without irradiation. Furthermore, the RT-induced apoptosis was decreased in control cells after p53 knockdown, consistent with HR cells. Based on the findings, the more radioresistance with less apoptosis and greater ROS scavenging ability in HR might be contributed to the decreased p53 at least in part.

MDM2 has been reported to be a predictor of prostate carcinoma outcome (Khor et al. 2005) and is a negative regulator of p53 (Jones et al. 1995, Levav-Cohen et al. 2005). Inhibition of MDM2 expression may suppress prostate progression and increase the response to treatment reported in some studies (Wang et al. 2003, Bianco et al. 2004, Mu et al. 2004). In the study, the increased MDM 2 was associated with the decreased p53 in HR prostate cancer cells. We demonstrated that down-regulation of MDM2 by genistein significantly increased the cytotoxicity and radiosensitivity of HR prostate cancer cells, combined with increased p53 expression. 
Therefore, MDM2 is likely to play a role in the radioresistance of HR.

AR plays an important role in the tumorigenesis of prostate cancer, even for HR prostate cancers (Grossmann et al. 2001, Zegarra-Moro et al. 2002). Chen et al. (2004) reported that an increase in AR mRNA and protein was necessary to convert prostate cancer growth from a hormone-sensitive to a hormonerefractory stage. Here, we found that HR cells had higher AR expression. There is increasing evidence that p53 may directly regulate androgen signaling (Sengupta \& Wasylyk 2001, Shenk et al. 2001). To ensure the effect, we analyzed the consequences of p53 overexpression on AR expression by the transfection of $\mathrm{V}_{\mathrm{p} 53}$ Furthermore, because MDM2 has recently been shown to catalyze AR ubiquitination and proteolysis in vivo (Lin et al. 2002, Cha et al. 2005, Gaughan et al. 2005), we further examined whether HR prostate cancer had altered interaction between MDM2 and AR, which might be responsible for the increased AR. The results showed that p53 is an important regulator of AR expression, but the association between MDM2 and AR is not significantly changed.

By the experiments in vitro and in vivo, the results reveal some interesting findings. Long-term androgen deprivation might induce HR prostate cancer cells with more aggressive tumor growth and radioresistance. The decreased p53 and the associated increased AR and MDM2 may be crucial in the underlying mechanisms. Moreover, regulation of the expressions of p53 and MDM2 should be the promising treatment strategies for relative radioresistant prostate cancer.

\section{Acknowledgement}

The authors declare that there is no conflict of interest that would prejudice the impartiality of this scientific work.

\section{References}

Achanta G \& Huang P 2004 Role of p53 in sensing oxidative DNA damage in response to reactive oxygen speciesgenerating agents. Cancer Research 64 6233-6239.

Agus DB, Cordon-Cardo C, Fox W, Drobnjak M, Koff A, Golde DW \& Scher HI 1999 Prostate cancer cell cycle regulators: response to androgen withdrawal and development of androgen independence. Journal of National Cancer Institute 91 1869-1876.

Bianco R, Caputo R, Caputo R, Damiano V, De Placido S, Ficorella C, Agrawal S, Bianco AR, Ciardiello F \& Tortora G 2004 Combined targeting of epidermal growth factor receptor and MDM2 by gefitinib and antisense
MDM2 cooperatively inhibit hormone-independent prostate cancer. Clinical Cancer Research 10 4858-4864.

van Bokhoven A, Varella-Garcia M, Korch C, Johannes WU, Smith EE, Miller HL, Nordeen SK, Miller GJ \& Lucia MS 2003 Molecular characterization of human prostate carcinoma cell lines. Prostate 57 205-225.

Brown JM \& Attardi LD 2005 The role of apoptosis in cancer development and treatment response. Nature Reviews. Cancer 5 231-237.

Burchardt M, Burchardt T, Shabsigh A, Ghafar M, Chen MW, Anastasiadis A, de la Taille A, Kiss A \& Buttyan R 2001 Reduction of wild type p53 function confers a hormone resistant phenotype on $\mathrm{LNCaP}$ prostate cancer cells. Prostate 48 225-230.

Cha TL, Qiu L, Chen CT, Wen Y \& Hung MC 2005 Emodin down-regulates androgen receptor and inhibits prostate cancer cell growth. Cancer Research 65 2287-2295.

Chang C, Saltzman A, Yeh S, Young W, Keller E, Lee HJ, Wang C \& Mizokami A 1995 Androgen receptor: an overview. Critical Reviews in Eukaryotic Gene Expression 5 97-125.

Chen CD, Welsbie DS, Tran C, Baek SH, Chen R, Vessella R, Rosenfeld MG \& Sawyers CL 2004 Molecular determinants of resistance to antiandrogen therapy. Nature Medicine 10 33-39.

Chen MF, Chen WC, Wu CT, Lin PY, Shau H, Liao SK, Yang CT \& Lee KD 2006a p53 status is a major determinant of effects of decreasing peroxiredoxin I expression on tumor growth and response of lung cancer cells to treatment. International Journal of Radiation Oncology, Biology, Physics 66 1461-1472.

Chen MF, Lin CT, Chen WC, Yang CT, Chen CC, Liao SK, Liu JM, Lu CH \& Lee KD $2006 b$ The sensitivity of human mesenchymal stem cells to ionizing radiation. International Journal of Radiation Oncology, Biology, Physics 66 244-253.

Colombel M, Radvanyi F, Blanche M, Abbou C, Buttyan R, Donehower LA, Chopin D \& Thiery JP 1995 Androgen suppressed apoptosis is modified in $p 53$ deficient mice. Oncogene 10 1269-1274.

Craft N, Chhor C, Tran C, Belldegrun A, DeKernion J, Witte ON, Said J, Reiter RE \& Sawyers CL 1999 Evidence for clonal outgrowth of androgen-independent prostate cancer cells from androgen-dependent tumors through a two-step process. Cancer Research 59 5030-5036.

Cronauer MV, Schulz WA, Burchardt T, Ackermann R \& Burchardt M 2004 Inhibition of p53 function diminishes androgen receptor-mediated signaling in prostate cancer cell lines. Oncogene 23 3541-3549.

Gaughan L, Logan IR, Neal DE \& Robson CN 2005 Regulation of androgen receptor and histone deacetylase 1 by Mdm2-mediated ubiquitylation. Nucleic Acids Research 33 13-26.

Grossmann ME, Huang H \& Tindall DJ 2001 Androgen receptor signaling in androgen-refractory prostate cancer. Journal of National Cancer Institute 93 1687-1697. 
Hall EJ 2000 In Radiology for the Radiologist, p 347Ed EJ Hall., 5 Philadelphia: JB Lippincott.

Hara T, Miyazaki J, Araki H, Yamaoka M, Kanzaki N, Kusaka M \& Miyamoto M 2003 Novel mutations of androgen receptor: a possible mechanism of bicalutamide withdrawal syndrome. Cancer Research 63 149-153.

Jones SN, Roe AE, Donehower LA \& Bradley A 1995 Rescue of embryonic lethality in $M d m 2$-deficient mice by absence of p53. Nature 378 206-208.

Khor LY, Desilvio M, Al-Saleem T, Hammond ME, Grignon DJ, Sause W, Pilepich M, Okunieff P, Sandler H \& Pollack A 2005 MDM2 as a predictor of prostate carcinoma outcome: an analysis of Radiation Therapy Oncology Group Protocol 8610. Cancer 104 962-967.

Lee AK 2006 Radiation therapy combined with hormone therapy for prostate cancer. Seminars in Radiation Oncology 16 20-28.

Levav-Cohen Y, Goldberg Z, Zuckerman V, Grossman T, Haupt S \& Haupt Y 2005 C-Abl as a modulator of p53. Biochemical and Biophysical Research Communications 331 737-749.

Li M, Zhang Z, Hill DL, Chen X, Wang H \& Zhang R 2005 Genistein, a dietary isoflavone, down-regulates the MDM2 oncogene at both transcriptional and posttranslational levels. Cancer Research 65 8200-8208.

Lin HK, Altuwaijri S, Lin WJ, Kan PY, Collins LL \& Chang C 2002 Proteasome activity is required for androgen receptor transcriptional activity via regulation of androgen receptor nuclear translocation and interaction with coregulators in prostate cancer cells. Journal of Biological Chemistry 277 36570-36576.

Mu Z, Hachem P, Agrawal S \& Pollack A 2004 Antisense MDM2 sensitizes prostate cancer cells to androgen deprivation, radiation, and the combination. International Journal of Radiation Oncology, Biology, Physics 58 336-343.

Pollack A, Salem N, Ashoori F, Hachem P, Sangha M, von Eschenbach AC \& Meistrich ML 2001 Lack of prostate cancer radiosensitization by androgen deprivation. International Journal of Radiation Oncology, Biology, Physics 51 1002-1007.

Polyak K, Xia Y, Zweier JL, Kinzler KW \& Vogelstein B 1997 A model for p53-induced apoptosis. Nature 389 300-305.

Roach M III 1999 Current status of androgen suppression and radiotherapy for patients with prostate cancer. Journal of Steroid Biochemistry and Molecular Biology $69239-245$.
Sablina AA, Budanov AV, Ilyinskaya GV, Agapova LS, Kravchenko JE \& Chumakov PM 2005 The antioxidant function of the p53 tumor suppressor. Nature Medicine 11 1306-1313.

Schellhammer PF, Venner P, Haas GP, Small EJ, Nieh PT, Seabaugh DR, Patterson AL, Klein E, Wajsman Z, Furr B et al. 1997 Prostate specific antigen decreases after withdrawal of antiandrogen therapy with bicalutamide or flutamide in patients receiving combined androgen blockade. Journal of Urology 157 1731-1735.

Sengupta S \& Wasylyk B 2001 Ligand-dependent interaction of the glucocorticoid receptor with p53 enhances their degradation by Hdm2. Genes and Development 15 2367-2380.

Shenk JL, Fisher CJ, Chen SY, Zhou XF, Tillman K \& Shemshedini L 2001 p53 represses androgen-induced transactivation of prostate-specific antigen by disrupting hAR amino- to carboxyl-terminal interaction. Journal of Biological Chemistry 276 38472-38479.

Tepper CG, Boucher DL, Ryan PE, Ma AH, Xia L, Lee LF, Pretlow TG \& Kung HJ 2002 Characterization of a novel androgen receptor mutation in a relapsed CWR22 prostate cancer xenograft and cell line. Cancer Research 62 6606-6614.

Tilley WD, Buchanan G, Hickey TE \& Bentel JM 1996 Mutations in the androgen receptor gene are associated with progression of human prostate cancer to androgen independence. Clinical Cancer Research 2 277-285.

Tulard A, Hoffschir F, de Boisferon FH, Luccioni C \& Bravard A 2003 Persistent oxidative stress after ionizing radiation is involved in inherited radiosensitivity. Free Radical Biology and Medicine 35 68-77.

Veldscholte J, Berrevoets CA, Brinkmann AO, Grootegoed JA \& Mulder E 1992 Anti-androgens and the mutated androgen receptor of LNCaP cells: differential effects on binding affinity, heat-shock protein interaction, and transcription activation. Biochemistry 31 2393-2399.

Wang H, Yu D, Agrawal S \& Zhang R 2003 Experimental therapy of human prostate cancer by inhibiting MDM2 expression with novel mixed-backbone antisense oligonucleotides: in vitro and in vivo activities and mechanisms. Prostate 54 194-205.

Zegarra-Moro OL, Schmidt LJ, Huang H \& Tindall DJ 2002 Disruption of androgen receptor function inhibits proliferation of androgen-refractory prostate cancer cells. Cancer Research 62 1008-1013. 